\title{
ESTUDO DE CASO DA APLICAÇÃO DE CONJUNTO SECCIONADOR DE BAIXA TENSÃO PARA SECCIONAMENTODEÁREAS ALAGADAS (ENCHENTES)
}

\author{
Álvaro Pereira Milani - alvaromilani93@gmail.com \\ Bruno Flores Farinazzo - brunoflored@icloud.com \\ Fabio Batista de Oliveira - oliveirabf@yahoo.com.br \\ Mateus de Sousa Cardoso - mateuscardoso@energisa.com.br \\ Paulo Henrique Silva Lopes -paulohenrique022@hotmail.com
}

\section{RESUMO}

Este artigo tem por objetivo analisar e propor uma solução prática e aplicável para o sistema elétrico que sofre com desligamentos decorrentes de chuvas e alagamentos em Cataguases/MG. Foi utilizado materiais do acervo eletrônico e dados técnicos de uma Concessionária do interior de Minas Gerais e aplicou-se um seccionador de baixa tensão em locais com histórico de alagamentos. Esta solução permitiu reduzir a abrangência das ocorrências técnicas, garantindo assim maior qualidade de vida para a população que ali vivem.

Palavras-Chave:Áreas alagadas (enchentes); Baixa Tensão; Seccionador.

\section{INTRODUÇÃO}

É comum, na região da Zona da Mata Mineira e em regiões de outros estados por todo o país, alagamentos de grandes proporções causados pelas chuvas constantes e volumosas do período de chuvas. De acordo com Alves et al. (2002) e Paiva (1997), no Sudeste, as chuvas mais intensas e que geram cheia em níveis elevados dos rios e, consequentemente enchentes,ocorrem entre os meses de outubro a março do ano subsequente, representando mais de $80 \%$ do total anual das chuvas.

O estudo de caso em questão está relacionado a cidade de Cataguases/MG, onde as enchentes são constantes e atingem níveis elevados, causando diversos problemas à cidade, sendo um deles o corte do fornecimento de energia elétrica em locais onde as águas atingem o padrão de entrada (medidores de energia) dos consumidores, que ocorre como medida preventiva e protetiva, já que o contato da rede elétrica com a água pode causar choques elétricos, bem como danificar os equipamentos eletrônicos/eletromecânicos de propriedade da Concessionária de Energia Elétrica. 
Para minimizar os impactos das interrupções em alguns locais específicos e que sempre são afetados pela subida do rio, o objetivo deste artigo é demonstrar a aplicação e melhorias de um seccionador de baixa de tensãoinstalado em postes de distribuiçãopara proporcionar o seccionamento rápido e seguro da rede elétrica, sem que haja a necessidade de deixar clientesnão afetados pelos alagamentos com o fornecimento interrompido até a redução do nível dos rios ou até a realização de ações de redução da abrangência (abertura de jumpers na rede de baixa tensão - BT). Estes equipamentos foram instalados nos becos do bairro Beira Rio, na cidade de Cataguases/MG, como medida de seccionamento apenas da parte baixa do bairro, deixando a avenida principal - que possui toda a área comercial do bairro, com energia normal durante todo o período das cheias.

\section{REVISÃO DE LITERATURA}

Conforme disposto no PRODIST - Módulo 8, seção 8.2, capítulo 5, subitem 5.8.5, é realizada anualmente a apuração dos Desempenho Global de Continuidade - DGC pela ANEEL, que é o órgão regulador do setor de Distribuição de Energia Elétrica no país, e publicado até abril de cada ano. Este índice é obtido através da razão dos valores realizados de DEC e FEC por seus respectivos limites, e após sua apuração compõe o ranking da continuidade onde as empresas são classificadas, de acordo com seu porte (quantidade de clientes) e o índice realizado (quanto menor o índice DGC melhor a empresa se mostrou no período de apuração e será mais bem classificada). Conforme a ANEEL (2016), “(...), o DGC visa comparar o desempenho de uma distribuidora em relação às demais empresas do país. $\mathrm{O}$ indicador permite avaliar o nível da continuidade da distribuidora (...)”.

Para as Distribuidoras é muito importante estar mais bem colocado no ranking da continuidade pois este fato vai além simplesmente do índice apurado, mas também está relacionado a possibilidade de ganhos financeiros pelo melhor desempenho período de apuração, através do Fator X e de seu Componente Q. De acordo com a ANEEL (2015), “O Fator $\mathrm{X}$ tem como objetivo primordial a garantia de que o equilíbrio estabelecido na revisão tarifária entre receitas e despesas eficientes seja mantido nos reposicionamentos tarifários subsequentes". Já o componente Q, visa ser um mecanismo de incentivo a melhoria da qualidade do serviço prestado pelas distribuidoras, conforme ANEEL (2015) através do PRORET - Procedimentos de Regulação Tarifária, Módulo 2, Submódulos 2.5 e 2.5A, de acordo com o ano da revisão tarifária da distribuidora. 
Diante deste cenário cada vez mais competitivo e de comparação, as empresas Distribuidoras de energia buscam rotineiramente desenvolver soluções que reduzam o impacto de eventos externos e que geram interrupções a seus clientes e, consequentemente, trazendo impactos aos seus indicadores de continuidade, de forma a garantir o cumprimento dos índices de qualidade do fornecimento (DEC e FEC), impostos pelo órgão regulador.

O PRODIST Módulo 8 é subdividido em duas seções. O artigo em questão está relacionado a seção 2, referente a Qualidade do Serviço prestado pelas Distribuidoras em termos de duração (DIC-DMIC-DEC) e frequência (FIC-FEC). Conforme o PRODIST, Módulo 8, Seção 8.2 (2018), temos:

○ DIC - Duração de Interrupção Individual por Unidade Consumidora ou por Ponto de Conexão, expressa em horas e centésimos de hora;

○ FIC - Frequência de Interrupção Individual por Unidade Consumidora ou por Ponto de Conexão, expressa em número de interrupções e centésimos do número de interrupções;

- DMIC - Duração máxima de Interrupção Contínua por Unidade Consumidora ou por Ponto de Conexão expressa em horas e centésimos de hora;

○ DEC - Duração Equivalente de Interrupção por Unidade Consumidora, expressa em horas e centésimos de hora;

○ FEC - Frequência Equivalente de interrupção por Unidade Consumidora, expressa em número de interrupções e centésimos do número de interrupções.

De acordo com o exposto acima, a apuração dos indicadores de continuidade é realizada de forma individualizada (DIC e FIC) e, através destes indicadores individuais é realizada a consolidação dos indicadores coletivos (DEC e FEC), que medem a duração e a frequência média que cada unidade consumidora da Distribuidora teve seu fornecimento de energia elétrica interrompido no período de apuração. Abaixo, na Figura 1,é possível conhecer as fórmulas de cálculo do DEC e FEC, conforme PRODIST Módulo 8, seção 8.2, item 5.5 (2018): 
Figura 1 - Fórmula DEC e FEC

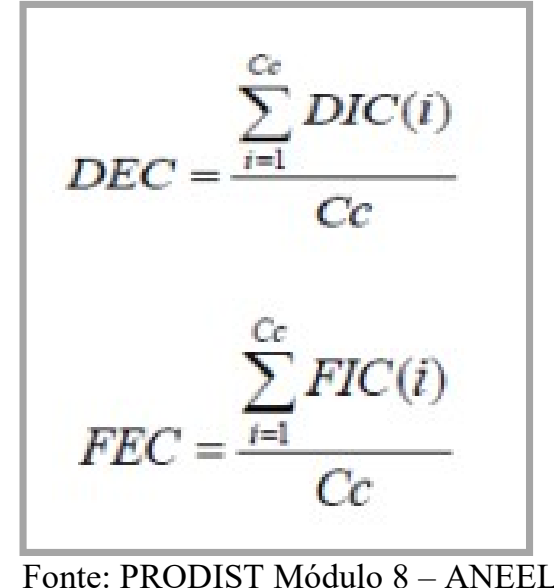

Onde:

$\mathrm{i}$ = índice de unidade consumidoras atendidas em BT ou MT faturadas do conjunto;

$\mathrm{Cc}=$ número total de unidades consumidoras faturadas do conjunto no período de apuração, atendidas em BT ou MT;

Para o correto entendimento e interpretação do cálculo dos indicadores de continuidade coletivos é necessária a compreensão do conceito de agrupamento dos consumidores de cada área de concessão. Conforme PRODIST - Módulo 1 (2008), temos a descrição de conjunto de unidades consumidoras como "Agrupamento de unidades consumidoras, aprovado pela ANEEL e pertencente a uma mesma área de concessão ou permissão".

Atualmente, a regra de formação de conjuntos de unidades consumidoras ou conjuntos elétricos tem relação com as Subestações de Distribuição (SED) e os critérios para formação dos mesmos, conforma PRODIST Módulo 8, são:

i. Abrangência do conjunto deve ser as redes média tensão - MT à jusante da SED e de propriedade da distribuidora.

ii. SED que possuam números de unidades consumidoras igual ou inferior a 1.000 clientes devem ser agrupadas a outras, formando um único conjunto.

iii. SED com número de unidades consumidoras superior a 1.000 e igual ou superior a 10.000 podem ser agregadas a outras, formando um único conjunto.

iv. A agregação de SED deve obedecer ao critério de contiguidade das áreas. 
v. É vedada a agregação de duas ou mais SED cujos números de unidades consumidoras sejam superiores a 10.000

vi. Mediante aprovação da ANEEL, poderão formar diferentes conjuntos SED que atendam a áreas não contíguas, ou que atendam a subestações MT/MT.

Vale lembrar que para cada conjunto elétrico de uma Distribuidora de Energia Elétrica existem limites regulatórios para os indicadores de continuidade (DEC e FEC), ou seja, indicadores máximos que em média as unidades consumidoras de determinados conjuntos podem ter seu fornecimento interrompido e por um tempo máximo determinado.

Conforme ANEEL (2015), a definição de limites é a criação de "Indicadores definidos pela ANEEL para aferir a qualidade do fornecimento de energia elétrica no conjunto de unidades consumidoras da área de atuação de cada distribuidora. Consideram a duração e frequência das interrupções no fornecimento do serviço". Estes limites são definidos através da realização de audiências públicas em fase de revisões tarifárias, por concessionária, que ocorrem de 4 em 4 anos ou de 5 em 5 anos, a depender do contrato de concessão de cada distribuidora. Após as revisões tarifárias, são publicadas resoluções autorizativas com os limites de DEC e FEC para cada conjunto.

\section{METODOLOGIA}

A pesquisa a qual se refere este estudo está pautada no acervo disponível em meios digitais, catálogos de fornecedores de materiais elétricose conteúdo dos órgãos reguladores (Agência Nacional de Energia Elétrica - ANEEL e Ministério de Minas e Energia - MME), dados técnicos de registros de ocorrência de Distribuidora de Energia Elétrica do interior de Minas Gerais, buscando identificar as ocorrências significativas e o impacto aos consumidores. A proposta em se aplicar uma seccionadora em rede de baixa tensão motiva-se pelo fato da característica do bairro em estudo, cujo possui uma avenida principal em um relevo mais alto e vários becos com relevos mais baixos, estando assim com maior vulnerabilidade a ações externas e ambientais. A aplicação, inclusive, garante o correto seccionamento da rede, desligamento apenas os becos atingidos por enchentes e inundações, bem como garantindo o fornecimento de energia a avenida principal, que abriga os principais comércios daquele bairro.

\section{CARACTERIZAÇÃO DO PROBLEMA}


No final de 2019 e início de 2020 várias cidades foram assoladas por enchentes consecutivas, trazendo além dos transtornos normais ocasionados pelas enchentes, interrupções no fornecimento de energia. Em Cataguases/MG não foi diferente. Em regiões da cidade que tem topografia mais baixas, normalmente há a necessidade de desligamento das redes por questões de segurança da população, onde a altura da água atingiu o conjunto de medição dos clientes. Esta não é uma realidade apenas da zona da mata de Minas Gerais, onde esta necessidade ocorre em várias regiões do país mas, especificamente neste estudo, é contextualizado de maneira geral a abrangência do Rio Pomba, que é a principal bacia hidrográfica do município, bem como os impactos causados em situações de enchentes.

\subsection{Bacia Hidrográfica do Município}

O município de Cataguases está situação na zona da mata mineira e, segundo o Instituto Brasileiro de Geografia e Estatística- IBGE, a população estimada para o município em 2020 é de 75.540 pessoas.

Como pode ser observado na imagem abaixo, além do próprio município de Cataguases, diversos outros municípios da zona da mata mineira também são abastecidos pelo Rio Pomba.

Figura 2-Mapa de municípios e Bacias Hidrográficas dos municípios 


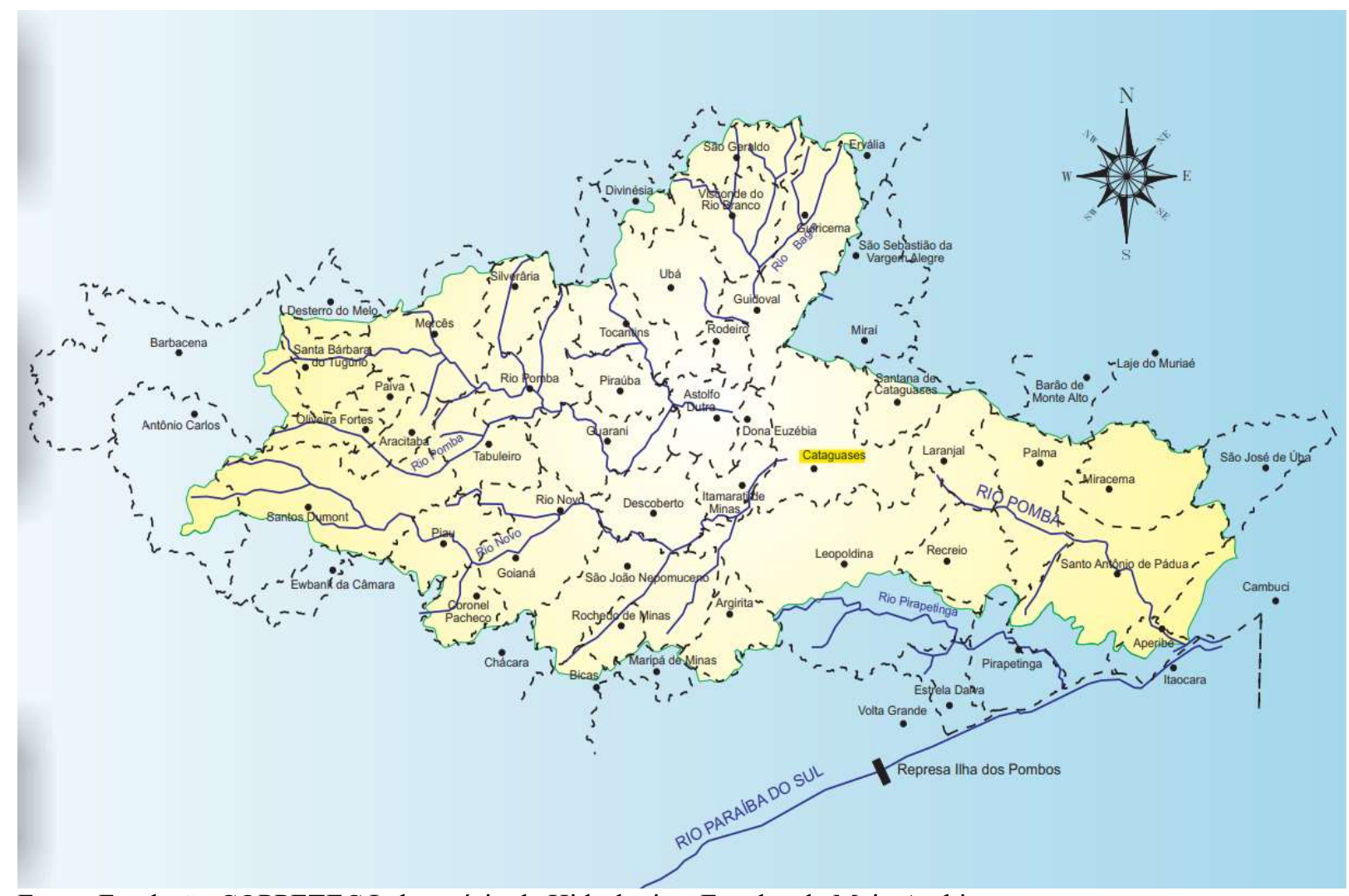

Fonte: Fundação COPPETEC Laboratório de Hidrologia e Estudos de Meio Ambiente

É possível observar pelo mapa acima que diversos outros municípios possuem paridade com o município de Cataguases e possuem características semelhante, como por exemplo o atendimento pelo Rio Pomba. Desta forma, considerando os municípios de um mesmo estado, com ações de um mesmo governo estadual, estima-se que a aplicação da metodologia deste estudo seja útil aos municípios vizinhos.

\subsection{Impactos das chuvas no município de Cataguases/MG e região}

O município de Cataguases/MG, situado na zona da mata mineira, sofreu no ano de 2020 três enchentes de grandes proporções entre os meses de janeiro a março, provocando alagamentos e, consequentemente, interrupções de energia como forma preventiva ao sistema elétrico e em proteção a população.

Abaixo seguem algumas notícias do ano de 2020, que evidenciam os impactos sofridos pela população da zona da mata mineira, no qual se encontra o município ora estudado: 
Figura 3 - Reportagens sobre impacto das enchentes na Zona da Mata Mineira

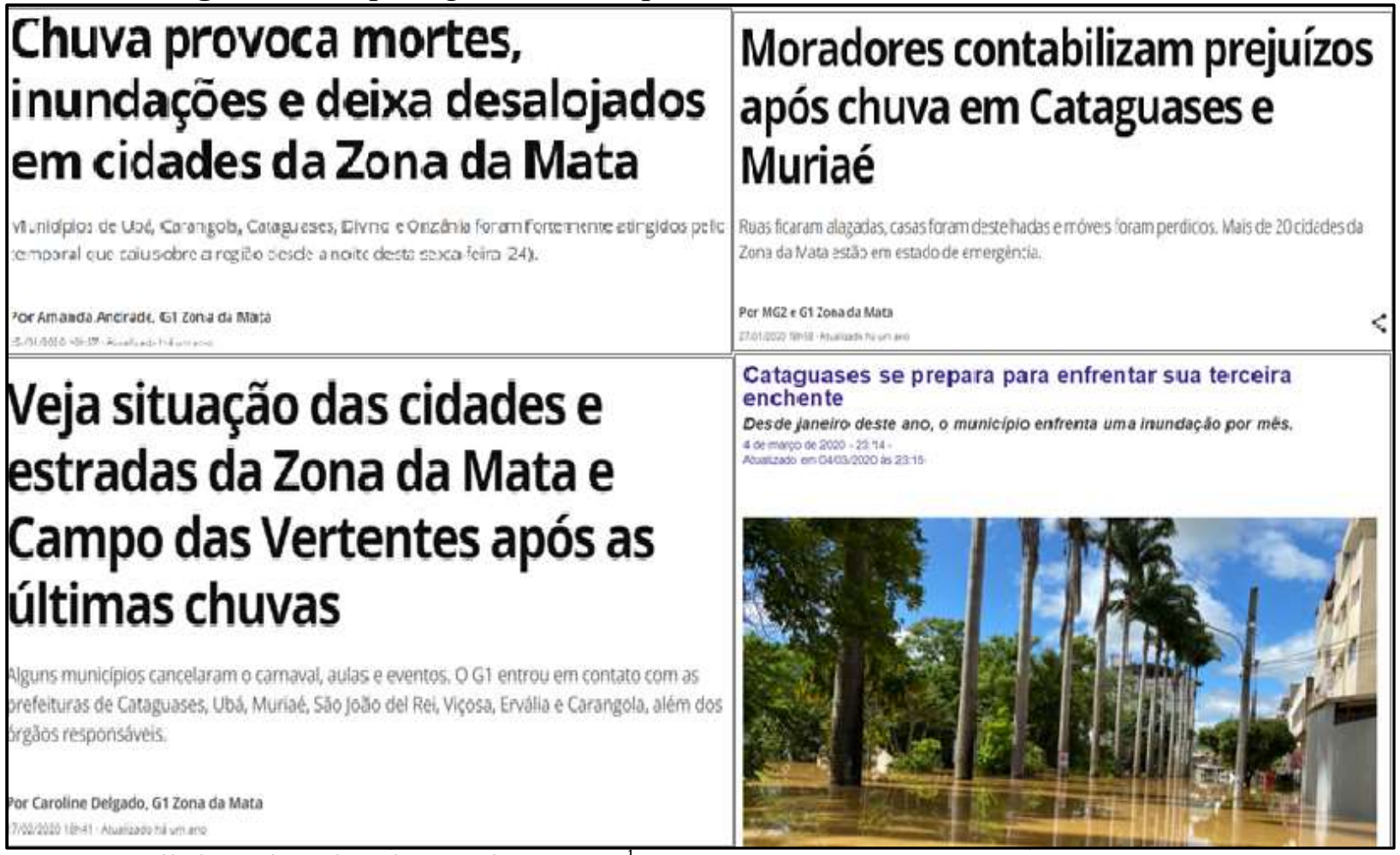

Fonte: Compilado e adaptado pelospróprios Autores

Mas, infelizmente, a situação não é exclusiva apenas do município mineiro, mas sim de um cenário nacional, cujo ao longo dos anos não foi providenciado pelos órgãos legisladores e executivos, ações voltadas para mitigar e eliminar agravamentos por chuvas e inundações.

Conforme cita a reportagem abaixo, ilustrado pela Figura 4, pelo Portal G1ocorrida no estado do Acre, "O desligamento da rede elétrica é uma medida de segurança para a população", logo, estas medidas extremas fazem parte de um conjunto de soluções de rupturas que buscam garantir a segurança da população, contudo, impacta em outros fatores qualitativos e quantitativos na apuração de indicadores de continuidade.

Figura 4 - Interrupção no fornecimento devido a enchente no ACRE

\footnotetext{
${ }^{1}$ Montagem a partir de imagens da internet de importantes veículos de comunicação regional e nacional. Disponível em:

- $\quad<$ https://g1.globo.com/mg/zona-da-mata/noticia/2020/01/25/chuva-provoca-mortes-inundacoes-edeixa-desalojados-em-cidades-da-zona-da-mata-veja-fotos.ghtml $>$. Acesso em 25 de maio e 2021.

- $\quad<$ https://g1.globo.com/mg/zona-da-mata/noticia/2020/01/27/moradores-contabilizam-prejuizos-aposchuva-em-cataguases-e-muriae.ghtml>. Acesso em: 25 de maio de 2021.

- $\quad<$ https://g1.globo.com/mg/zona-da-mata/noticia/2020/02/17/veja-situacao-das-cidades-e-estradas-dazona-da-mata-e-campo-das-vertentes-apos-as-ultimas-chuvas.ghtml>.Acesso em 25 de maio de 2021.

- $\quad<$ https://www.marcelolopes.jor.br/site/2020/03/04/cataguases-se-prepara-para-enfrentar-sua-terceiraenchente/>.Acesso em 25 de maio e 2021.
} 


\section{Mais de 10,4 mil consumidores estão sem energia elétrica devido à cheia dos rios no Acre}

\section{0 desligamento da rede elétrica é uma medida de segurança para a população, segundo Energisa.}

Por Tácita Muniz, G1 AC - Rio Branco

22/02/2021 09h41 · Atualizado há 3 meses

Fonte: Portal G1 Acre. ${ }^{2}$

A realidade ocorrida no Acre também ocorreu com municípios mineiros atendidos por outra Concessionária de Minas Gerais em 2017 e em municípios Maranhenses atendidos em 2019, conforme reportagens abaixo, ilustrados nas Figuras 5 e 6:

Figura 5- Fornecimento de energia cortado em municípios em Minas Gerais

\section{Energia elétrica foi cortada em cidades inundadas na Zona da Mata}

Técnicos da Cemig tiveram dificuldades para chegar a alguns municípios devido às interdiç̃oes nas estradas. Religação está sendo gradativa depois de afastados riscos de eletrocussões

EM Estado de Minas

postado em 04/12/2017 21:02/ atualizado em 04/12/2017 21:58

Fonte: Jornal Estado de Minas

${ }^{2}$ Disponível em: <https:/g1.globo.com/ac/acre/noticia/2021/02/22/mais-de-104-mil-consumidores-estao-semenergia-eletrica-devido-a-cheia-dos-rios-no-acre.ghtml.> Acesso em 25 de maio de 2021.

${ }^{3}$ Disponível em: <https://www.em.com.br/app/noticia/gerais/2017/12/04/interna_gerais,921961/energia-eletricafoi-cortada-em-cidades-inundadas-na-zona-da-mata.shtml $>$. Acesso em 10 de maio de 2021 
Figura 6- Fornecimento de energia cortado em municípios do Maranhão

\section{Alagamentos ou Inundação? Saiba como se proteger!}

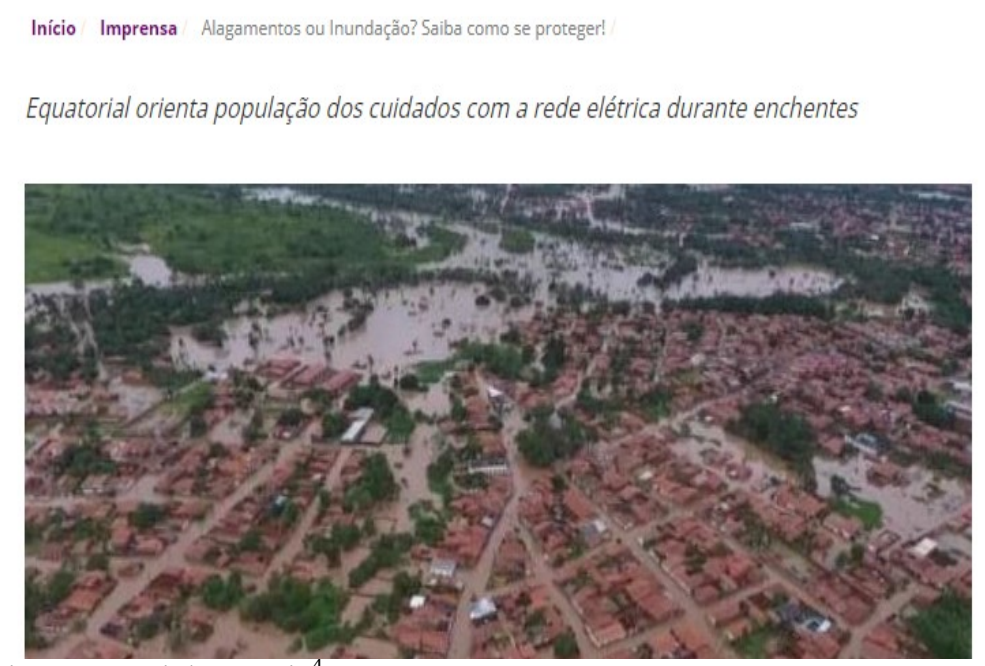

Fonte: Site Equatorial Energia ${ }^{4}$

De voltaà realidade da Distribuidora da zona da mata de Minas, objeto deste artigo, conforme citado anteriormente e ilustrado nas reportagens da Figura 3,ocorreram entre o final de 2019 e início de 2020 várias enchentes consecutivas, as quais geraram interrupções no fornecimento de energia para as regiões submersas, seja por motivo de segurança, seja por motivos técnicos (curtos-circuitos, queima de equipamentos etc.). O Quadro I, demonstrado abaixo,apresenta a listagem das interrupções ocorridas, início, término e duração das interrupções registradasno bairro Beira Rio, no município de Cataguases - Minas Gerais, em específico na avenida principal e nos becos existentes no bairro, que são os locais mais propícios à inundação e alagamentos durante as cheias do rio, uma vez que possuem baixo relevo e proximidade com o Rio Pomba.

Quadro 1 - Registro de interrupções ocorridas em função das enchentes

\footnotetext{
${ }^{4}$ Disponível em: < https://ma.equatorialenergia.com.br/2019/08/alagamentos-ou-inundacao-saiba-como-seproteger/>. Acesso em 28 de maio de 2021.
} 


\begin{tabular}{|c|c|c|c|}
\hline Enchente & Inicio interrupção & Término interrupção & Duração Interrupção \\
\hline 1 & $25 / 01 / 202011: 02$ & $26 / 01 / 202011: 00$ & 23,97 \\
\hline 2 & $13 / 02 / 202023: 40$ & $15 / 02 / 202000: 10$ & 24,50 \\
\hline 3 & $05 / 03 / 202017: 48$ & $06 / 03 / 202010: 10$ & 16,37 \\
\hline \multicolumn{4}{|r|}{ Duração total do Eventos } \\
\hline
\end{tabular}

Fonte: Distribuidora de energia elétrica do interior de Minas Gerais

Estas interrupções listadas acima geraram impacto aos indicadores de continuidade (DEC e FEC) e compensações financeiras na ordem de R \$ 8.750,00 (oito mil, setecentos e cinquenta reais) aos clientes que tiveram seu fornecimento de energia interrompido (extrapolação do limite de DIC dos clientes). De fato, há interesse mútuo pela resolução desta questão e, não apenas pela questão financeira das compensações por descumprimento dos índices de continuidade exigidos pela ANEEL, mas também por toda a necessidade de se garantir a qualidade e direitos de seus consumidores.

A figura 7, representada abaixo,elaborada pelos próprios autores com a utilização da ferramenta Google Earth, ilustra a região citada do bairro Beira Rio, onde é possível observar a avenida principal (destaque em amarelo) e os becos que ocorrem os alagamentos (destaque em laranja). Sem a instalação do seccionador de BT, ambas as regiões eram afetadas pelo desligamento da energia elétrica. Com a instalação do seccionador, apenas as regiões destacadas em laranja são desligadas.

Figura 7- Mapa do Google Earthcom a região afetada pelas enchentes 


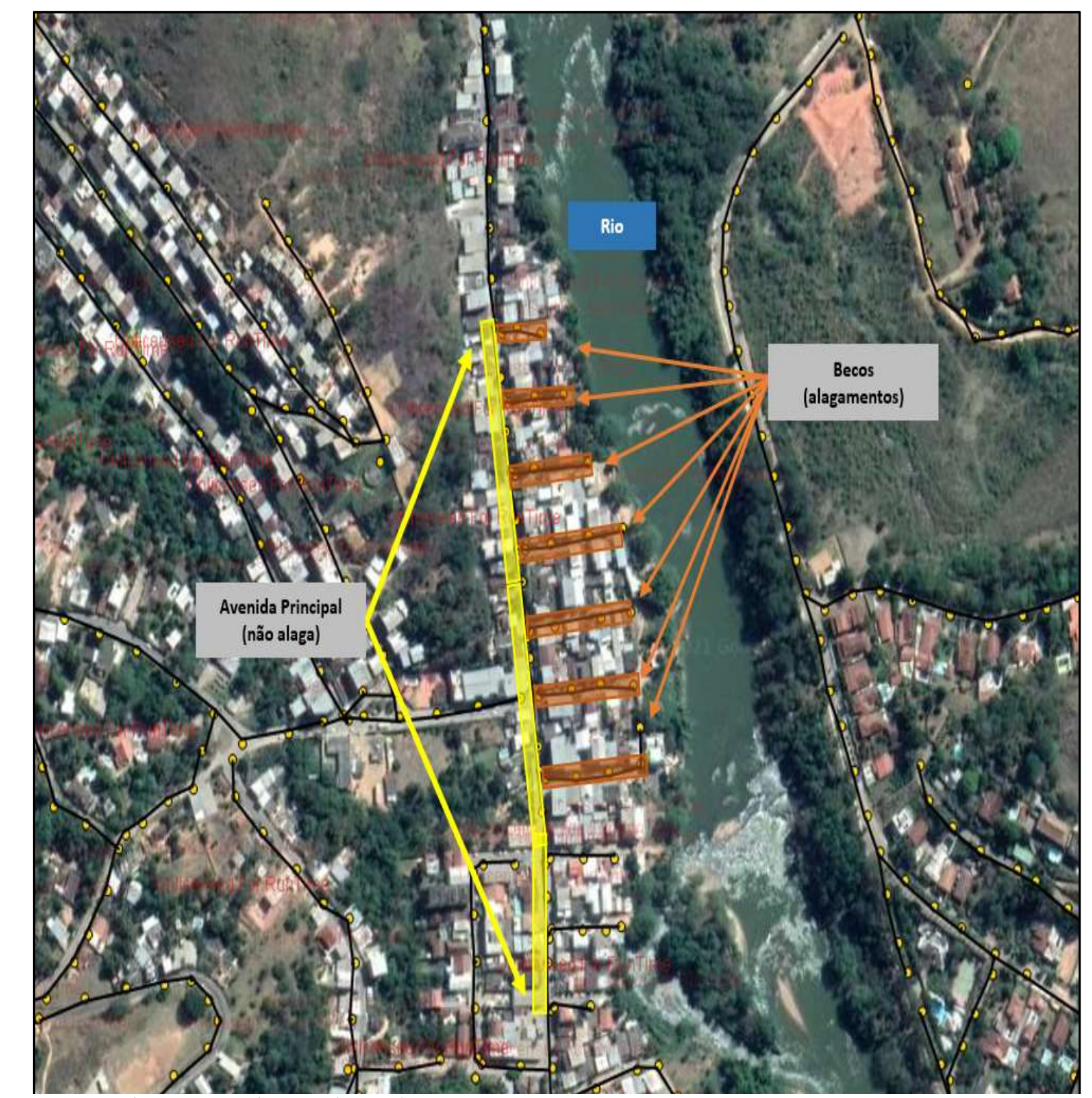

Fonte: Próprios Autores via Google Earth

Adicional ao impacto nos indicadores, as interrupções num momento complicado como uma enchente geram impactos sociais e insatisfação por parte dos clientes. Inclusive, se considerado que esta avenida principal abriga os principais comércios daquele bairro, como açougues, supermercados, padarias etc., os impactos são infinitamente maiores. Sendo assim, além do sofrimento com as cheias, a população ainda corria risco de ficar sem insumos essenciais que dependesse de energia elétrica. 
O artigo está direcionado a uma cidade da zona mata mineira e com possibilidade de utilização em outras localidades similares, cuja infraestrutura sofre com catástrofes ambientes e/ou situações inerentes ao seu controle. A fim de reduzir os impactos das interrupções de energia elétricaaos clientes, em especial aos clientes ligados aos circuitos com trechos alagados pelas enchentes e que não foram afetados por ela (avenida principal do bairro), foi pensadoem uma solução para realização do seccionamento da baixa tensão de forma interromper apenas os trechos de rede que alimenta os becos, que são as áreas afetadas pelas enchentes, e não todo o alimentador - que também contempla a avenida principal.

Desta forma, a aplicação do seccionador de BT nos referidos becos proporciona a distribuidora de energia elétrica maior gestão de risco e mitigação de impactos, garantindo assim o menor impacto possível nos indicadores de continuidade de fornecimento, bem como propiciando à população daquele bairro maior diversificação do atendimento, mantendo assim a área de maior concentração de clientes e comércios atendidas pela rede principal.

Nas figuras 8, 9 e 10, destacadas abaixo,sãoilustrados os componentes utilizados, o modo de preparação do equipamento (caixa + seccionador) e a instalação em campo.

Figura 8- Seccionador de BT

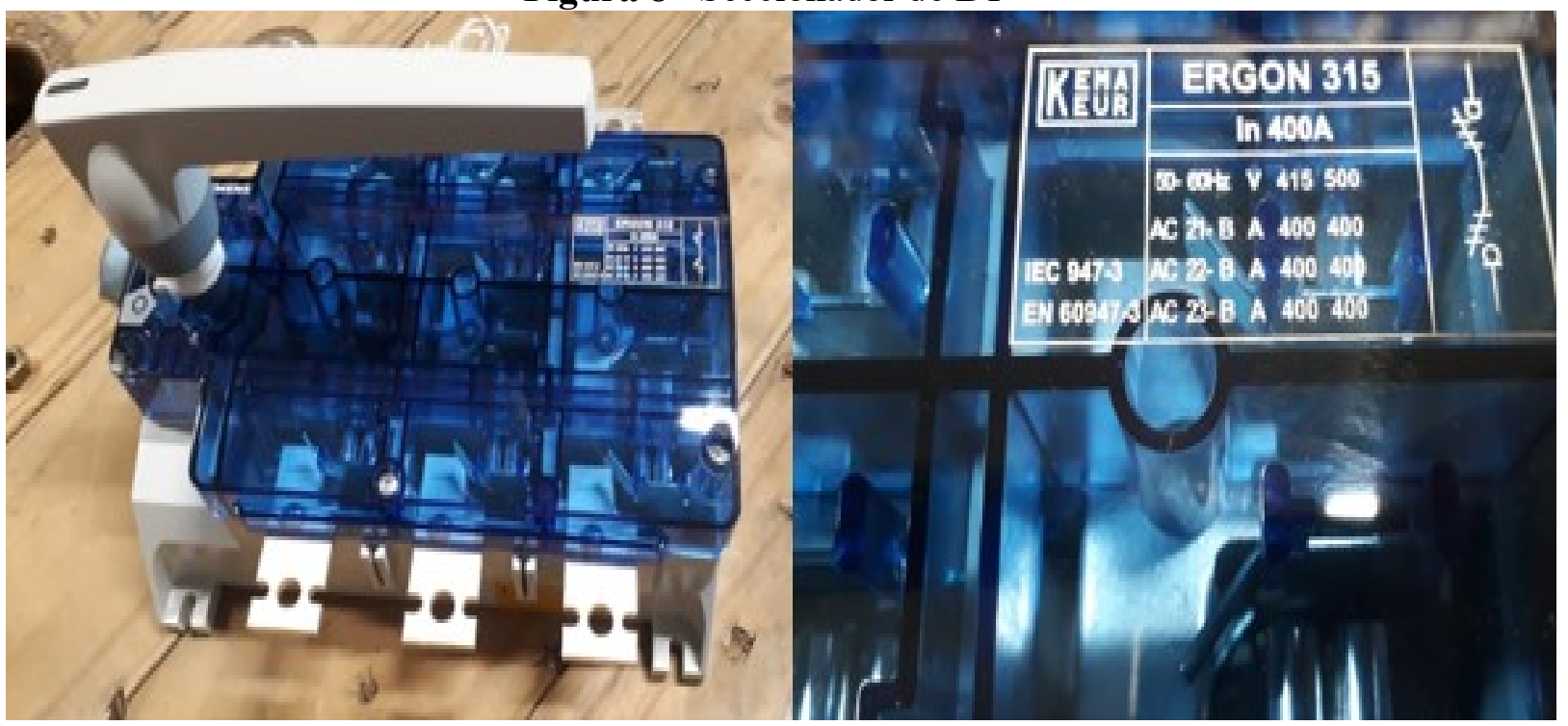

Fonte: Próprios Autores

Figura 9- Caixa para armazenamento e fixação do seccionador de BT 


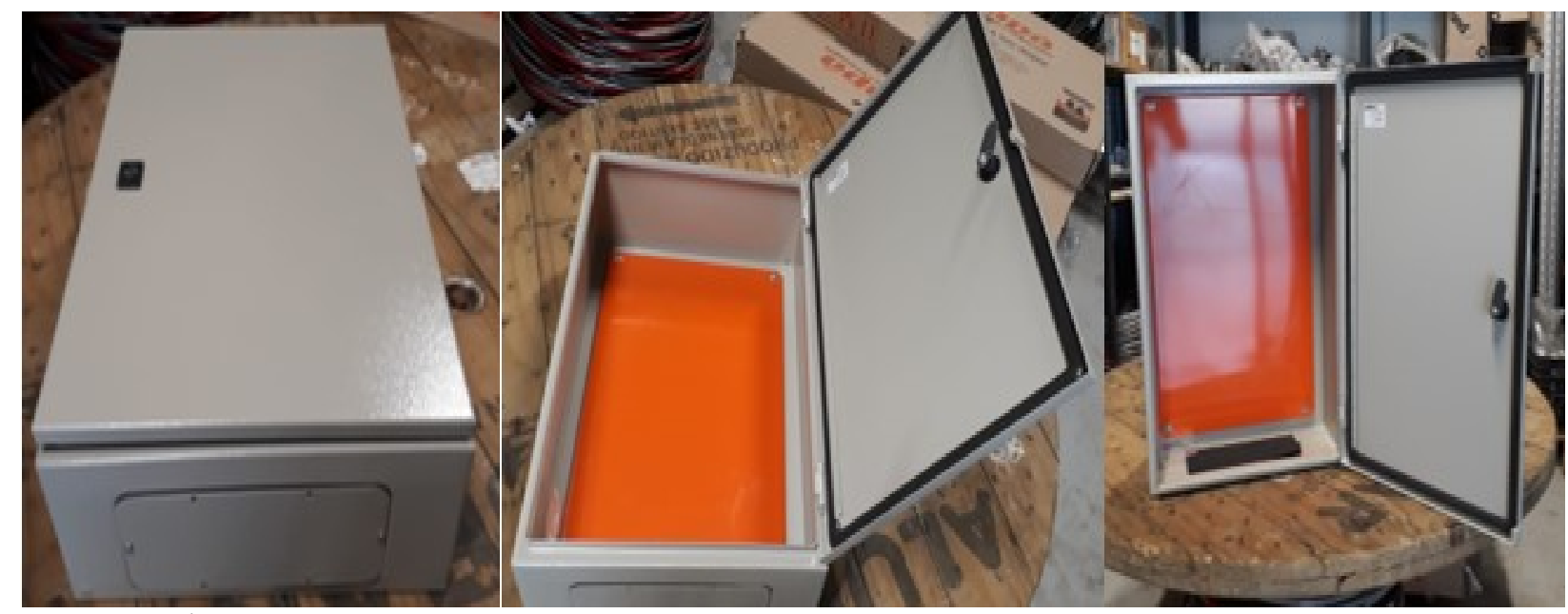

Fonte: Próprios Autores

Figura 10- Preparação e montagem do seccionador de BT

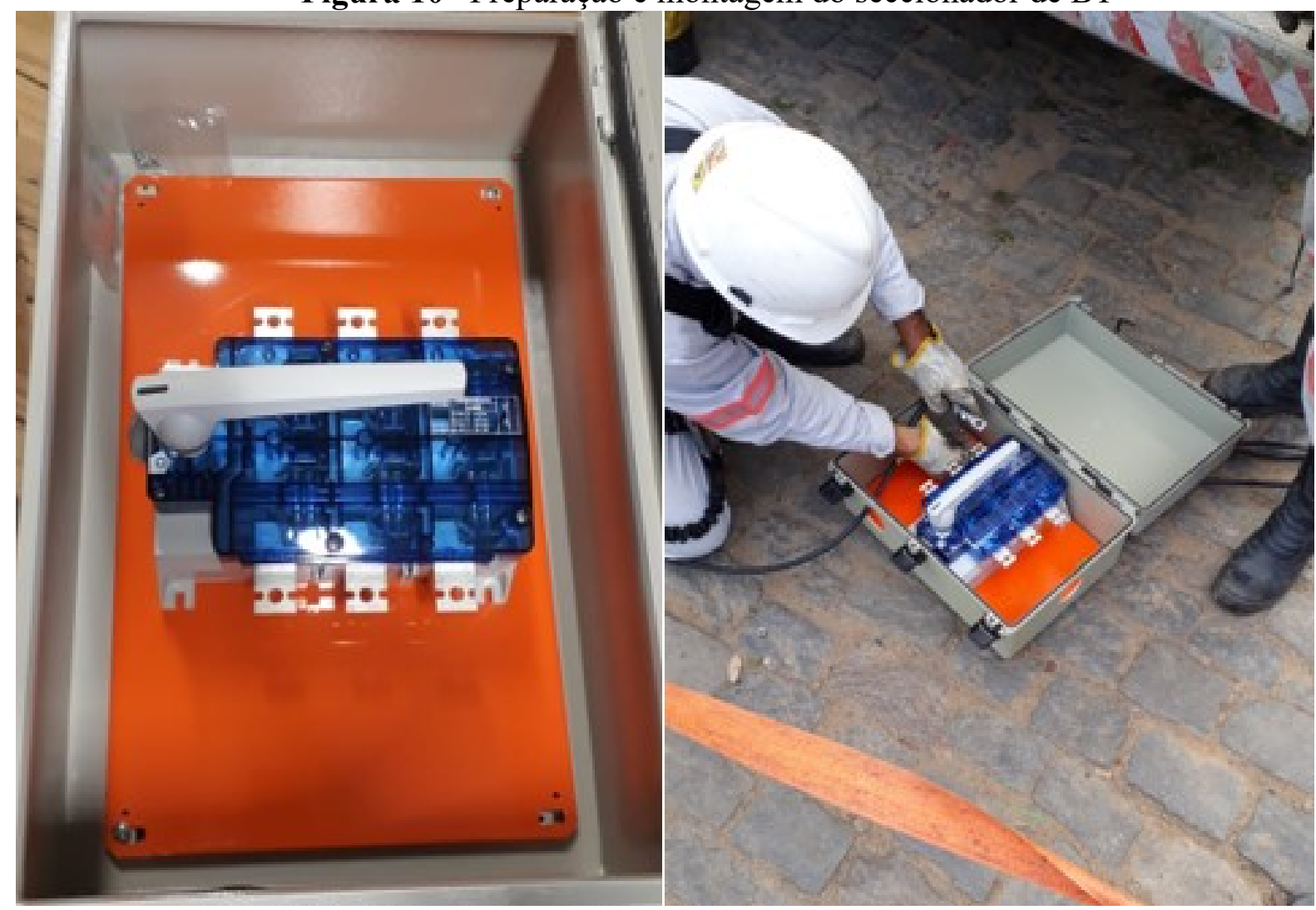

Fonte: Próprios Autores

\subsection{Resultados e Discussão}


A instalação ocorreu pelas equipes próprias da Concessionária da cidade de Cataguases/MG, em março/2021, nas derivações dos circuitos da avenida principal para os becos, cujo funcionamento da seccionadora tem por objetivo separar os becos alagados/inundados dos trechos não alagados/inundados. Um fator importante, que justifica o objetivo deste trabalho, é que os equipamentos são operados manualmente e de forma individual, logo, apesar do bairro conter vários becos próximos ao Rio Pomba, há a possibilidade de atuações estratégias e direcionadas em pontos específicos, de acordo com a necessidade, sem que haja desligamento da chave geral, afetando clientes cujo não possui risco iminente nem foram afetados pelas cheias.

$\mathrm{Na}$ figura 11 é possível visualizar a atuação da concessionária instalando a seccionadora de BT nos becos do bairro Beira Rio, no município de Cataguases/MG:

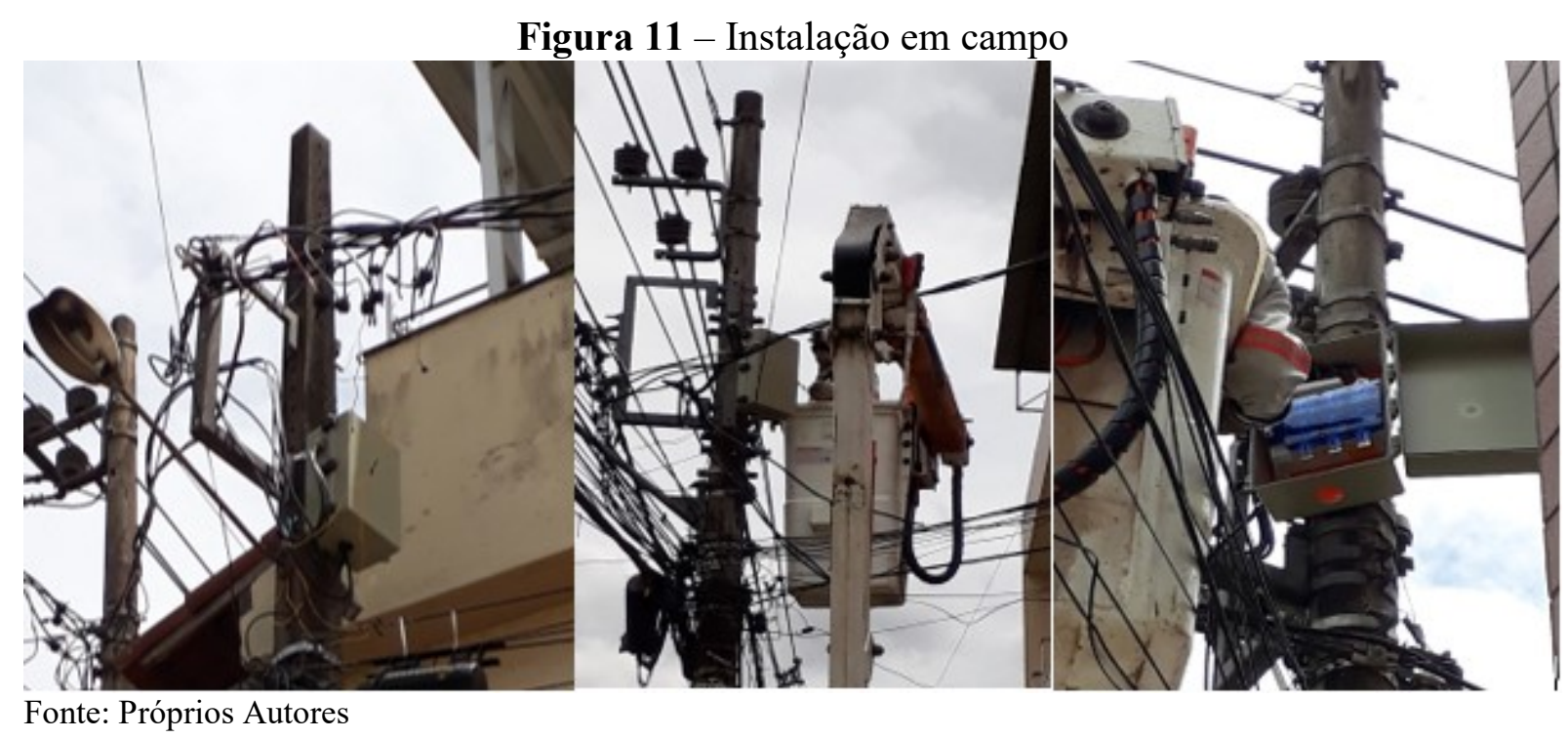

Estima-se que o custo global dos equipamentos utilizados para desenvolvimento da seccionadora de baixa tensão gira-se em torno de $\mathrm{R} \$ 700,00$ a 1.000,00 cada e sua instalação garante para a concessionária o remanejamento ideal das cargas e seccionamento estratégico de regiões alagadas.

\section{CONCLUSÃO}

De acordo com o desenvolvimento deste artigo foi possível observar que o município de Cataguases/MG, bem como o bairro Beira Rio deste município, fazem parte de um 
conjunto de municípios da Zona da Mata Mineira que são atendidos pela Bacia Hidrográfica Rio Pomba.

Foi elencado no estudo os impactos globais, sociais e quantitativos para a Distribuidora, destacando o princípio da continuidade do fornecimento que a agência reguladora impõe como forma de manter o maior número possível de horas com energia elétrica aos brasileiros. Sendo assim, os indicadores DEC e FEC são fatores preponderantes se a Distribuidora deseja obter índices de qualidades elevados e, sem hipocrisia, garantir a concessão por mais tempo, já que o descumprimento destes importantes indicadores são índices que geram multas e - até mesmo, a perda da concessão federal para distribuição de energia elétrica.

Com base no tema estudado, restou-se claro a necessidade iminente de providências tecnológicas e degrande impacto para reduzir a abrangência de desligamentos oriundos de enchentes de grandes proporções no bairro estudado. O seccionador de BT surge no ramo da Distribuição de energia elétrica como método paraseccionar as áreas mais prejudicadas, em outras palavras, é possível fazer uma analogia ao ditado popular "separar o joio do trigo". No que tange ao sistema elétrico daquela região, esta aplicação nos trechos atingidos por fenômenos naturais propicia à Concessionária ações específicas voltadas para cada local, bem como minimizando os impactos à população e garantindo a redução dos indicadores de continuidade, regulados pela ANEEL.

Conclui-se então, após o desenvolvimento deste importante estudo, que a aplicação do seccionador de BT possui aplicabilidade e características essenciais para a operação do sistema elétrico de potência, especialmente em regiões com características específicas, como no caso deste bairro estudado que sofre constantemente com enchentes e alagamentos. Adicionalmente, estima-se que o custo global para aplicação individual das seccionadoras seja menor que R\$1.000,00 e os dados quantitativos com a redução dos indicadores DEC e FEC poderão ser melhor apurados com futuras ocorrências de mesmo cunho naqueles locais, onde os equipamentos entrarão em operação e, desta forma, possibilitando a comparação do antes e depois. 


\section{REFERÊNCIAS BIBLIOGRÁFICAS}

AGÊNCIA NACIONAL DE ENERGIA ELÉTRICA - ANEEL. Serviço Público de Distribuição de Energia Elétrica. Disponível em: https://www.aneel.gov.br/distribuicao2 Acesso em 25 de maio de 2021.

AGÊNCIA NACIONAL DE ENERGIA ELÉTRICA - ANEEL. PRODIST Módulo 8. Disponível em: https://www.aneel.gov.br/modulo-8. Acesso em 15 de maio de 2021.

AGÊNCIA NACIONAL DE ENERGIA ELÉTRICA - ANEEL. PRODIST Módulo 8. Disponível em: https://www.aneel.gov.br/documents/656827/14866914/M\%C3\%B3dulo_8-Revis\%C3\%A3o_10/2f7cb862e9d7-3295-729a-b619ac6baab9. Acesso em 13 de maio de 2021.

AGÊNCIA NACIONAL DE ENERGIA ELÉTRICA - ANEEL. DGC - Desempenho Global de Continuidade (Ranking ANEEL-2019). Disponível em: https://www.aneel.gov.br/ranking-2019. Acesso em 13 de maio de 2021.

AGÊNCIA NACIONAL DE ENERGIA ELÉtriCA - ANEEL. PRORET - Submódulo 2.5A. Acesso em 13 de maio de 2021.

AGÊNCIA NACIONAL DE ENERGIA ELÉTRICA - ANEEL. PRORET - Submódulo 2.5. Disponível em: https://www.aneel.gov.br/proret-submodulos/-/asset_publisher/9GaPoqtgd9GK/content/submodulo-25/654800?inheritRedirect=false\&redirect $=$ http $\% 3 \mathrm{~A} \% 2 \mathrm{~F} \% 2 \mathrm{Fwww}$.aneel.gov.br\%2Fproretsubmodulos\%3Fp_p_id\%3D101_INSTANCE_9GaPoqtgd9GK\%26p_p_lifecycle\%3D0\%26p_p_state\%3Dnorm al\%26p_p_mode\%3Dview\%26p_p_col_id\%3D̄ column-2\%26p_p_col_count\%3D1. Acesso em 13 de maio de 2021.

AGEVAP - “Caderno de Ações Bacia do Rio Pomba”. Disponível em: https://www.ceivap.org.br/downloads/cadernos/Caderno\%205\%20-\%20Pomba.pdf. Acesso em 01 de junho de 2021.

ALVES, L.M.; MARENGO, J.A.; CAMARGO JR., H.; CASTRO, C. Início da estação chuvosa na região Sudeste do Brasil: Parte 1 Estudos observacionais. Revista Brasileira de Meteorologia, v.20, n.3, p.385-394, 2005.

Censo Brasileiro de 2018. Minas Gerais: IBGE, 2018. INSTITUTO BRASILEIRO DE GEOGRAFIA E ESTATÍSTICA (IBGE).

Climatempo - "Cheia dos rios no leste de MG, ES e Norte do RJ ainda preocupa". Disponível em: https://www.climatempo.com.br/noticia/2020/03/07/cheia-dos-rios-no-leste-de-mg-es-e-norte-do-rj-aindapreocupa-2244.Acesso em 12 de maio de 2021.

Climatempo - "Rios em alerta de transbordamento em MG, RJ e ES". Disponível em: https://www.climatempo.com.br/noticia/2020/03/05/rios-em-alerta-de-transbordamento-em-mg-rj-e-es2228. Acesso em 25 de maio de 2021.

CBN Amazônia - "Fornecimento de energia é suspenso para mais de dez mil pessoas devido a enchente dos rios no AC" Disponível em: https://cbnamazonia.com/cidades/rio-branco/fornecimento-de-energia-e-suspensopara-mais-de-dez-mil-pessoas-devido-a-enchente-dos-rios-no-ac. Acesso em 25 de maio de 2021.

Estado de Minas Gerais - "Energia elétrica foi cortada em cidades inundadas na zona da mata" Disponível em: https://www.em.com.br/app/noticia/gerais/2017/12/04/interna_gerais,921961/energia-eletrica-foi-cortadaem-cidades-inundadas-na-zona-da-mata.shtml . Acesso em 10 de maio de 2021.

Equatorial Energia - “Alagamentos ou inundação? Veja como se proteger!” Disponível em: https://ma.equatorialenergia.com.br/2019/08/alagamentos-ou-inundacao-saiba-como-se-proteger/. Acesso em 28 de maio de 2021.

Portal G1 - "Enchentes requer cuidados com a rede elétrica". Disponível em: http://g1.globo.com/brasil/noticia/2011/01/enchente-requer-cuidados-com-a-rede-eletrica.html. Acesso em 27 de maio de 2021. 
Portal G1 - "Prefeitura instala gabinete de crise após fortes chuvas em Cataguases”. Disponível em: https://g1.globo.com/mg/zona-da-mata/noticia/2020/03/05/prefeitura-instala-gabinete-de-crise-apos-forteschuvas-em-cataguases.ghtml. Acesso em 27 de maio de 2021.

Portal G1 - "Veja situação das cidades e estradas da zona da mata e campo das vertentes após as últimas chuvas". Disponível em: https://g1.globo.com/mg/zona-da-mata/noticia/2020/02/17/veja-situacao-das-cidadese-estradas-da-zona-da-mata-e-campo-das-vertentes-apos-as-ultimas-chuvas.ghtml.Acesso em 25 de maio de 2021.

Portal G1 -“Moradores contabilizam prejuízos após chuva em Cataguases e Muriaé”. Disponível em: https://g1.globo.com/mg/zona-da-mata/noticia/2020/01/27/moradores-contabilizam-prejuizos-apos-chuva-emcataguases-e-muriae.ghtml. Acesso em 25 de maio de 2021.

Portal Marcelo Lopes - "Cataguases se prepara para enfrentar sua terceira enchente”. Disponível em: https://www.marcelolopes.jor.br/site/2020/03/04/cataguases-se-prepara-para-enfrentar-sua-terceiraenchente/.Acesso em 25 de maio de 2021.

Portal G1 - "Chuva provoca inundações e deixa desalojados em cidades da zona da mata". Disponível em: https://g1.globo.com/mg/zona-da-mata/noticia/2020/01/25/chuva-provoca-mortes-inundacoes-e-deixadesalojados-em-cidades-da-zona-da-mata-veja-fotos.ghtml. Acesso em 25 de maio de 2021.

Portal G1 - "Mais de 10,4 mil consumidores estão sem energia elétrica devido a cheia dos rios no Acre" Disponível em: https:/g1.globo.com/ac/acre/noticia/2021/02/22/mais-de-104-mil-consumidores-estao-semenergia-eletrica-devido-a-cheia-dos-rios-no-acre.ghtml. Acesso em 25 de maio de 2021. 